\title{
The Characteristic of Water Injection Response to Complex Reservoir
}

\author{
Xiuguang Liang ${ }^{1, a}$, Yujun Lin ${ }^{2, b}$, Changjiang Fan ${ }^{1, c}$ \\ ${ }^{1}$ Research Institute of Petroleum Exploration and Development, Petrochina, China \\ ${ }^{2}$ China Oil and Gas Exploration and Development Company, China \\ alingxiuguang@petrochina.com.cn, ${ }^{b}$ lin.yujun@Salyanoil.com, ${ }^{c}$ fanchangjiang@cnpcint.com
}

Keywords: complex reservoir, validity, control factor, connection type

Abstract: Water injection is a main method in the development of oil field in order to obtain high recovery efficiency, especially for the complex reservoir. This paper is concerned with water injection development of complicated stratum reservoir. It introduced the special condition of the water injection area, and 5 factors influencing water injection result. By means of statistics, the paper concluded the common characteristic of validity of production wells response to injection wells and the difference of the validity for 6 aspects. The gap of the validity between different oil wells is big. By using comparative method, the paper summarizes that the reservoir formation connectivity is the key control factor to the validity, the basic stratum correlation is important. The conclusion can be used for the analysis of other oil field.

\section{The General Situation of the Water Injection Blocks}

The blocks started production in 1964 and started water injection in 1971. It stopped the injection in 1993.

The injection area is a blocked anticline. It includes two blocks $\left(\mathrm{NB}^{2}, \mathrm{NB}^{2}\right)$. The area is lower in southwest and higher in northeast. The main fault dips to southeast (Fig.1).

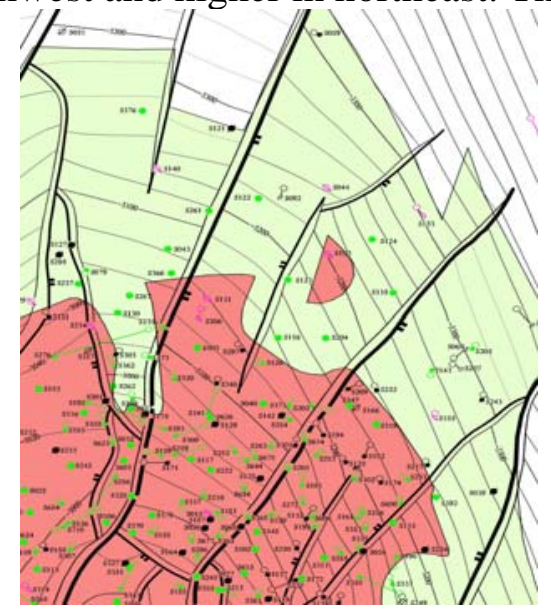

Fig.1 The structure map of the area

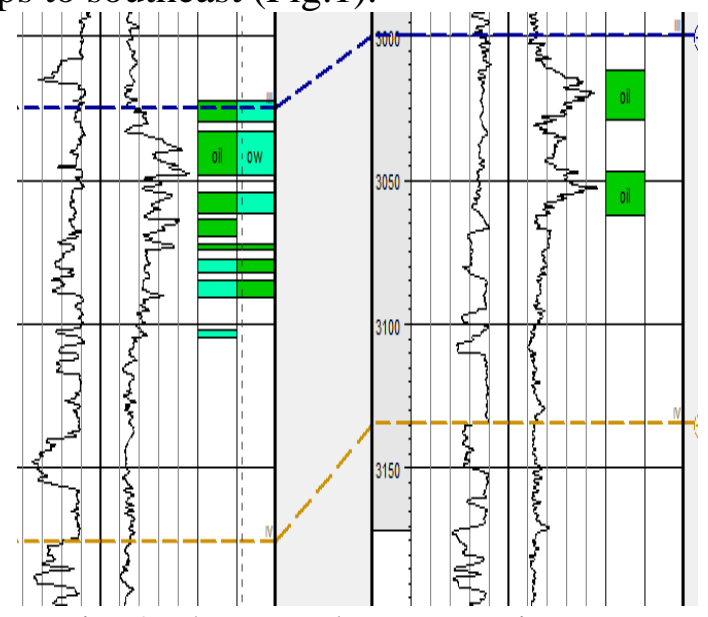

Fig. 2 The complex reservoir stratum

The oil production layers of water injection test area are zone I-VIII of Pliocene series, the water injection layers are zone I, II, III, IV, and the main layer is zone III.

The reservoir layer is mainly composed of point bar of river. The positive rhythm stratum consists of many silt layers. The single layer is thin and the average thickness is $3.0 \mathrm{~m}$. The stratum is composed of clay, silt, sandstone and gravel, etc. The layers change frequently in vertical and horizental direction. So it is difficult for us to determine the distribution of the layers (Fig. 2). It may be called the most complex reservoir formation.

According to the core analysis data, the reservoir layer is medium porosity and low permeability. The rock is mainly composed of feldspar and quartz. The grain size is fine to medium. The sorting of grains is poor to middle, and the shape of grains is angular to sub-rounded. The rock contains more clay content. The clay is mainly composed of montmorillonite (80\%). The rock has small pore throat 
radius and behaves double peak in radius-content diagram, which means the uniformity of the rock is poor (Photo1, Photo 2).

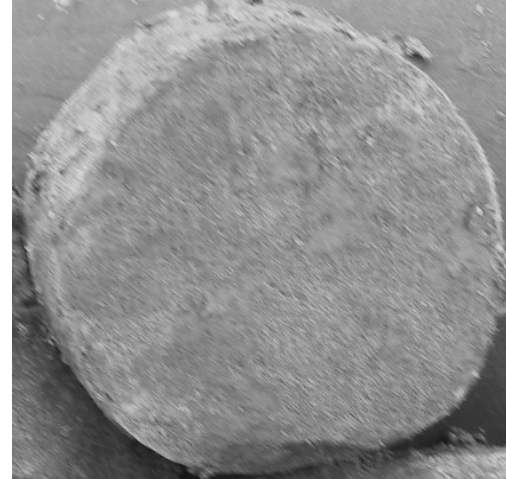

Photo 1 core sample

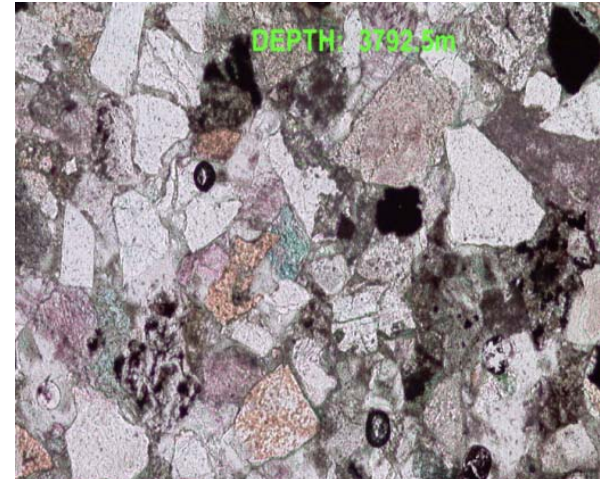

Photo 2 slice characteristic

The reservoir type belongs to constructure and lithologic reservoir shielded by fault. The relationship of oil-gas-water is very complex, different blocks and layers have different oil-gas-water system.

There are 64 wells in the water injection area. The OOIP is $15120 * 10^{3}$ tons. The recoverable reserve is $4540 * 10^{3}$ tons. The total oil produced until the last phase of water injection is $3040 * 10^{3}$ tons. It means that the recovery percent of reserves for OOIP and recoverable reserves is $20.0 \%$ and $67.0 \%$ respectively.

\section{The Characteristic of Production Well Response to Water Injection}

\section{The Production Well Validity}

All the production wells have validity after water injection. They behave the same performance (validity) that is concluded as "four increases and one decrease". The "four increases" are fluid, oil, water cut and formation pressure increase. The one decrease is GOR decrease.

\section{The Difference of Validity}

All the production wells have validity, but it is different for different wells, and the difference gaps for different wells are too big, they are analyzed as follows.

The period before production well response to water injection. This period of time is different for different production wells. The shortest is 3 months and the longest is 42 months. The average is 19.6 months.

The daily oil increase.The daily oil increase has big difference for different wells. According to the statistics of 24 response wells, there are 4 wells, or $16.7 \%$ of the total wells with a daily oil increase more than $10 \mathrm{~m}^{3}$; 3 wells, accounting for $12.5 \%$, with a daily oil increase more than $10-5 \mathrm{~m}^{3}$; 2 wells, accounting for $8.3 \%$, with a daily oil increase more than $5-3 \mathrm{~m}^{3} ; 7$ wells, accounting for $29.2 \%$, with a daily oil increase more than $3-1 \mathrm{~m}^{3}$, and 8 wells, accounting for $33.3 \%$, with a daily oil increase less than $1 \mathrm{~m}^{3}$.

The accumulative oil increase.Overall, the accumulative oil increase isn't much. The total increase of all production wells with validity is $85345 \mathrm{~m}^{3}$. The most oil increase for single well is $24171 \mathrm{~m}^{3}$. Among the 24 response wells, there are 2 wells, or $16.7 \%$ of the total wells with a total oil increase more than $20 * 10^{3} \mathrm{~m}^{3} ; 1$ well, accounting for $12.5 \%$, with a total oil increase $20-10 * 10^{3} \mathrm{~m}^{3}$; 2 wells, accounting for $8.3 \%$, with a total oil increase $10-5 * 10^{3} \mathrm{~m}^{3} ; 6$ wells, accounting for $29.2 \%$, with a total oil increase more than $5-1 * 10^{3} \mathrm{~m}^{3}$, and 13 wells, accounting for $33.3 \%$, with a total oil increase less than $1 * 10^{3} \mathrm{~m}^{3}$.

The period of validity of production well.The period of validity has big difference. 3 wells produced better for more than 15 years. They kept oil increase continuously. there are 2 wells with the period of validity for 5-10 years; 10 wells with 2-5 years and 7 wells with less than 2 years. Most production wells lost the validity because high water cut and/or low fluid production rate. 
The corresponding relation between production and injection wells.Some well production rate increase with the water injection rate goes high, and vice versa. The relation is clear. For example, the injection well 5131 and the production well 5122. 5131 started water injection on Nov. 1971. 5122 behaved validity after 18 months water injection. 5122 has four periods of fluid decrease corresponding to 4 periods of injection rate decrease of 5131. But some wells have no so clear relationship.

The type of production well validity. According to the characteristics of production well validity, there are three types of valid production wells. The first type is the recovery of shutdown wells, the production rate is 0 for these wells before water injection, and they have continuously validity after they respond to water injection. The second type is the short period validity well. The total production rate tendency is decrease, and there is short oil increase period in the total production time. The third type is the continuous validity well, The oil production rate is higher in the valid period than it in no-valid period.

\section{The Main Factor that Affect the Production Well Validity}

As mentioned above, the validity gap between different wells is big. What is the main control factor for it? The following factors are analyzed and the main factor is selected by comparing.

\section{The Water Injection Engineering on Ground}

These refer to how the production and injection wells are designed. There are 4 main factors associated with the design.

The injection and production well pattern. The well pattern is not perfect in the test. It does not belong to regular pattern such as four, five, or nine point well pattern, etc. there are 17 wells, accounting for $72.2 \%$ of the total production wells, belonging to one injection well related to one production well type. 7 wells, accounting for $27.8 \%$, belonging to two injection wells related to one production well type, and no production well is driven by 3 or more than 3 injection wells. The most extreme case is that some production wells weren't driven by any injection wells, and this situation made the water flooding reserve small.

Daily injection rate and water injectivity index. The water injection rate for injection wells has little difference except for a few wells. There are 1 well, accounting for $7.8 \%$ of the total injectors with injection rate less than $50 \mathrm{~m}^{3} / \mathrm{d}$; 0 well, accounting for $0 \%$, with injection rate $50-100 \mathrm{~m}^{3} / \mathrm{d}$; 8 wells, accounting for $57.1 \%$ with injection rate $100-150 \mathrm{~m}^{3} / \mathrm{d}$; 3 wells, accounting for $21.4 \%$, with injection rate $150-200 \mathrm{~m}^{3} / \mathrm{d}$, and 2 wells, accounting for $14.3 \%$, with injection rate more than 200 $\mathrm{m}^{3} / \mathrm{d}$. The average injection is $160 \mathrm{~m}^{3} / \mathrm{d}$. The water injectivity index is mainly focused (65\%) at $10-25$ $\mathrm{m}^{3} / \mathrm{M}$ Pa. d. The smallest is $2.9 \mathrm{~m}^{3} / \mathrm{M}$ Pa. $\mathrm{d}$, the largest is $81.9 \mathrm{~m}^{3} / \mathrm{M} \mathrm{Pa}$. d. The average is $21.9 \mathrm{~m}^{3} / \mathrm{M}$ Pa. d.

The well spacing between injection and production wells.Some well spacing is big. The percentage for the spacing longer than $500 \mathrm{~m}$ is $17.4 \%$, and $300-500 \mathrm{~m}$ is $30.4 \%$, and shorter than $300 \mathrm{~m}$ is $52.2 \%$. The longest spacing is $750 \mathrm{~m}$. Several injection wells are located in the outside. According to report, the ideal spacing is $200-300 \mathrm{~m}$ for this reservoir type.

The quality of water injected. The formation water out of production well is injected back to reservoir formation. By the laboratory test, the injection water quality is under standard requirement. The concentration of suspension solid is $38.4 \mathrm{mg} / \mathrm{l}$ (the standard requirement is $3.0 \mathrm{mg} / \mathrm{l}$ ). The median particle diameter is 2.7um that is bigger than standard requirement (2.0 um).

\section{The Water Injection Engineering Under-Ground}

It mainly refers to how to select layers of the injection and production wells to insure the high connectivity. In the injection test time, the oil field development was influenced by the political and economic situation, technology limit, and complex geology. There was a main problem that the technician make some layers not connect as connect ones. Based on the well logging curve characteristics and the geology meaning they present, now we come back to see the former layer correlation result, the total connect classes can be classified as three types. 
Type I. Type I is the best connection type. The shape of Production layer is same as the shape of injection layer, and the same relation for the upper and lower layers of the target stratum. This connection type reflects that the sedimentary face is more same for the two wells location, and the sedimentary environment evolution is resemblance. The percentage of the connective layers is estimated to be more than $80 \%$ (Fig. 3).

Type II. Type II is the transitional type from type I to type III. The shape of the two correlation wells is less similar than type I, and more similar than type III. Part of the single layers connects only. The percentage of connective layers is estimated to be $50-80 \%$ (Fig.4).

Type III. Type III is the worst connection type. The shape of Production layer is less same as the shape to injection layer, and the same for the upper and lower layers of the target layers. This connection type reflect the sedimentary environment changes frequently, the percentage of the connective layers is estimated to be less than 50\% (Fig.5).

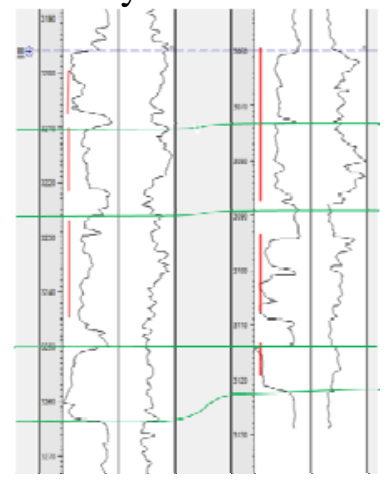

Fig.3 type I

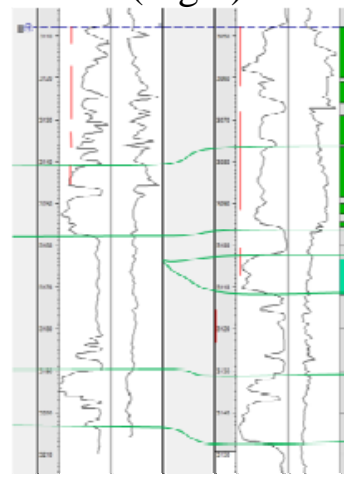

Fig.4 type II

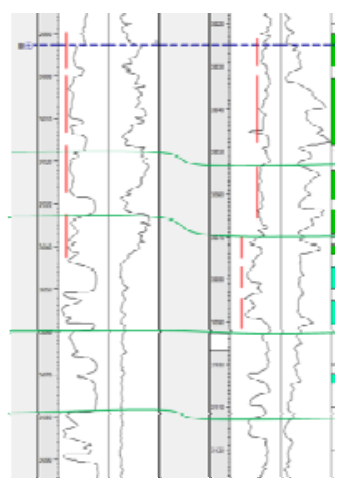

Fig.5 type III

\section{The Analysis of the Influence Factors}

The validity of production wells is largely different, the control factors were analyzed one by one and the key factor was revealed.

\section{The Influence of Reservoir Engineering on Ground}

Firstly, because of one production well is driven only by one or two injection wells in the test, and It isn't regular well pattern, the injection-production well pattern has little impact on validity. The production well validity gap is also little for different well spacing between injection and production wells (Fig.6). Secondly, the injection water quality affects all wells at the same manner. Thirdly, according to the figure, the distribution of points of the daily injection with the period before action and fluid or oil increase and accumulative oil increase presents dispersive characteristic, it infers the daily injection rate has little influence on these factors (Fig.7). Fourthly, the accumulative water injection has more action on the validity of production wells (Fig. 8).

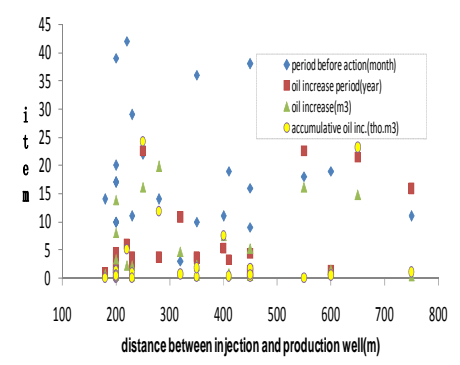

Fig. 6 Spacing-validity

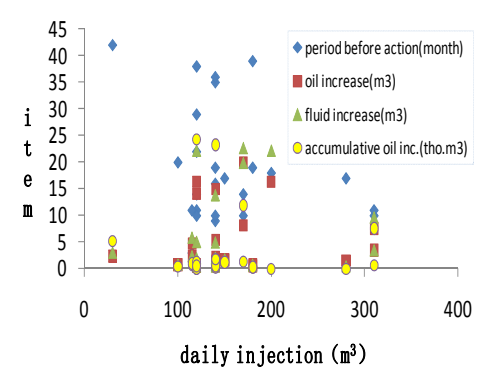

Fig. 7 Daily water injection-validity

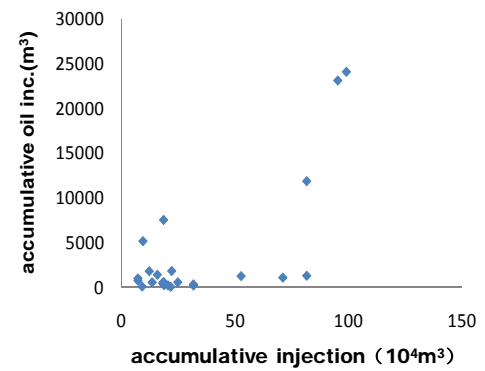

Fig. 8 Total injection-validity

\section{The Influence of Reservoir Engineering Under-Ground}

The better the layers connection was, the more oil the production well increased. It is analyzed as follows mainly.

Type I. There are 7 wells, accounting for $29.2 \%$ of the total production well, with type I. the period before action is short. The period of validity is long. The average daily oil increase, fluid 
Increase is the biggest in the three types. The water cut increase is much for most production wells. The accumulative oil increase is big. The injection result is the best in the three types. (Fig.9, Fig.10, Table 1).

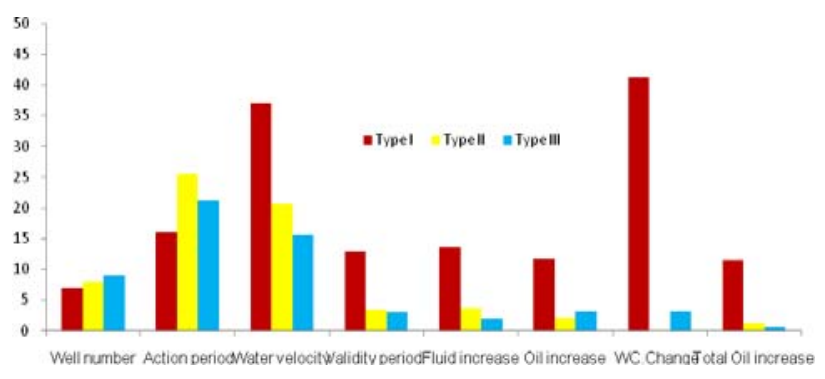

Fig.9 connection type-validity index

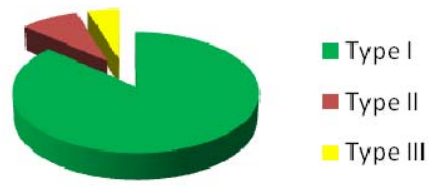

Fig.10 connection type-total oil increase

Type II. There are 8 wells, or 33.3\% accounting for the total production wells, with type II. The injection validity accounts for the middle of type I and type III. the period before action, The period of validity of production, accumulative oil increase, the average daily oil and fluid Increase is less than type I and more than type III. Water cut increase is small. The injection result is the middle in the three types. (Fig.9, Fig.10, Table 1).

Type III. There are 9 wells, or $37.5 \%$ accounting for the total production wells, with type III. The period before action is long. The period of validity of production well is short. The average daily oil and fluid Increase, the accumulative oil increase is little. Water cut increase is little. The injection result is the worst in the three types. (Fig.9, Fig10, Table 1).

Table 1 The validity index of different layer connection type

\begin{tabular}{|c|c|c|c|c|c|c|c|c|}
\hline Type & Well NO. & $\begin{array}{c}\text { Period } \\
\text { before } \\
\text { action } \\
\text { [month] }\end{array}$ & $\begin{array}{c}\text { Velocity of } \\
\text { water go } \\
\text { [m/month] }\end{array}$ & $\begin{array}{c}\text { Validity } \\
\text { period } \\
\text { [year] }\end{array}$ & $\begin{array}{c}\text { Fluid } \\
\text { increase } \\
\text { [m3/well.d] }]\end{array}$ & $\begin{array}{c}\text { Oil increase } \\
\text { [m3/well.d] }]\end{array}$ & $\begin{array}{c}\text { Change of } \\
\text { water cut } \\
{[\%]}\end{array}$ & $\begin{array}{c}\text { Total Oil } \\
\text { increase } \\
\text { [m3/well] }\end{array}$ \\
\hline TypeI & 7 & 16 & 37 & 12.9 & 13.6 & 11.6 & 41.1 & 11554 \\
\hline TypeII & 8 & 25.5 & 20.7 & 3.5 & 3.6 & 2.1 & -3.3 & 1158 \\
\hline TypeIII & 9 & 21.1 & 15.6 & 3 & 1.9 & 3.1 & 3.1 & 633 \\
\hline
\end{tabular}

\section{Conclusion}

The water injection test lasted for 20 years. The total result of water injection is not better. The accumulative oil increase is smaller than it is expected. The gap of validity of production wells is big. A few wells increase more oil. There are 5 factors influence the validity of production well. They have different impact on the validity. The injection-production well pattern, different well spacing between injection and production wells, the injection water quality has small impact on it in this field. The accumulative water injection and reservoir layer connection type have more action on the validity of production wells. Especially, the connection type is the key factor. To set up a better layer connection net is very important for the development of water injection driving reservoir.

\section{Reference}

[1] Lingyun Fang, Dexin Wan. The performance analysis for water injection of sandstone reservoir. (Petroleum Industry Press. Beijing 1998. In Chinese).

[2] Yi Wu, Huamin Wang, Shangyi Xue. The water injection development of complex block reservoir. (Petroleum Industry Press. Beijing 2007. In Chinese).

[3] Shenghe Wu. reservoir stratum Characterization and modeling. (Petroleum Industry Press. Beijing 2010. In Chinese).

[4] Xinghe Yu. The sedimentology of clastic rock reservoir stratum of oil field. (Petroleum Industry Press. Beijing 2008. In Chinese). 